\title{
Radiological evaluation of cervical spine involvement in rheumatoid arthritis
}

\author{
Andrei F. Joaquim, MD, PhD, ${ }^{1}$ Enrico Ghizoni, MD, PhD, ${ }^{1}$ Helder Tedeschi, MD, PhD, ${ }^{1}$ \\ Simone Appenzeller, MD, PhD, ${ }^{2}$ and K. Daniel Riew, MD ${ }^{3}$
}

\begin{abstract}
Departments of ${ }^{1}$ Neurology and ${ }^{2}$ Medicine and Rheumatology, State University of Campinas (UNICAMP), Campinas, São Paulo, Brazil; and ${ }^{3}$ Department of Orthopedic Surgery, Washington University School of Medicine and Barnes Jewish Hospital, Saint Louis, Missouri
\end{abstract}

\begin{abstract}
Cervical spine involvement commonly occurs in patients with rheumatoid arthritis (RA), especially those with inadequate treatment or severe disease forms. The most common site affected by RA is the atlantoaxial joint, potentially resulting in atlantoaxial instability, with cervical pain and neurological deficits. The second most common site of involvement is the subaxial cervical spine, often with subluxation, resulting in nerve root or spinal cord compression.

In this paper, the authors review the most commonly used plain radiographic criteria to diagnose cervical instabilities seen with RA. Finally, we discuss the advantages and disadvantages of cervical CT and MRI in the setting of cervical involvement in RA.
\end{abstract}

http://thejns.org/doi/abs/10.3171/2015.1.FOCUS14664

KEY WORDS upper cervical; rheumatoid arthritis; radiological evaluation

$\mathrm{R}$ HEUMATOID arthritis (RA) is a systemic inflammatory disease that predominantly affects adult women ( 2 to 4 times as frequently as men). ${ }^{17}$ Although this autoimmune condition involves mainly bone, joints, and ligaments, extra-articular involvement has been described in nearly every organ, including the lungs, eyes, skin, and vessels. ${ }^{16,18}$

The cervical spine is involved in up to $86 \%$ of patients with RA, especially in those with inadequate treatment or more severe forms of the disease. ${ }^{18,22,27,33,38,44}$ Cervical involvement is probably a consequence of the intense chronic synovitis that occurs in the joints, progressing to bone erosion and consequent ligamentous laxity and finally clinical and radiological instability. ${ }^{15,18}$

The most common site of involvement is the atlantoaxial region..$^{4,42,43}$ There is an important predilection for chronic inflammatory infiltration and pannus formation at the $\mathrm{C} 1-2$ joints that precedes bone destruction. This inflammatory process results in laxity of the ligamentous complex and loss of ligamentous restriction, leading to atlantoaxial instability. As a natural tendency, the head drops forward, resulting most commonly in anterior atlantoaxial subluxation (AAS) craniocervical kyphosis, decreasing the craniocervical angle..$^{15,18}$ Clinically, cervical pain can be secondary to instability or C-2 nerve root compression. Stroke and sudden death have been reported in patients with RA involvement of the upper cervical spine due to vertebrobasilar insufficiency.,38 Considering atlantoaxial instability, anterior AAS is the most common form, followed by lateral AAS, which represents about $20 \%$ of cases, and posterior AAS, which represents about $7 \%$ of all cases of AAS in association with RA. ${ }^{6}$ Posterior AAS generally occurs in the setting of an odontoid base erosion or fracture. Posterior subluxation is associated the highest rate of neurological deficits of all forms of AAS. ${ }^{18,28}$ Additionally, all cases of AAS can also be classified as reducible, partially reducible, or fixed, according to the response to traction or dynamic radiological studies.

ABBREVIATIONS $A A S=$ atlantoaxial subluxation; $A D I=$ atlantodental interval; $R A=$ rheumatoid arthritis; $S A S=$ subaxial subluxation . SUBMITTED September 21, 2014. ACCEPTED January 14, 2015. INCLUDE WHEN CITING DOI: 10.3171/2015.1.FOCUS14664.

DISCLOSURE Dr. Riew has direct stock ownership in Amedica, Benvenue, Expanding Orthopedics, Nexgen Spine, Osprey, Paradigm Spine, Spinal Kinetics, Spineology, Vertiflex, and PSD; has received clinical or research support for the study described (includes equipment or material) from AOSpine, Cerapedics, Medtronic, OREF, and Spinal Dynamics; has received royalties from Biomet, Medtronic, and Osprey; holds board membership in CSRS, KASS, Global Spine Journal, Spine Journal, and AOSpine International; has received payment for lectures (honoraria) from AOSpine, New England Spine Society Group, and NASS; and has received travel reimbursement from AOSpine, NASS, SRS, Broadwater, and Selby Spine. The other authors report no conflict of interest concerning the materials or methods used in this study or the findings specified in this paper. 
In some cases, atlantoaxial instability can progress and result in vertical migration of the odontoid into the cranial cavity-also known as cranial settling. Many other terms are found in the medical literature and used as synonyms for cranial settling, including basilar impression or invagination, vertical subluxation, atlantoaxial impaction, and superior migration of the odontoid. ${ }^{15}$

Lastly, cervical involvement in RA patients can also affect the subaxial cervical spine, defined as the segments from $\mathrm{C}-3$ to $\mathrm{C}-7$. The most common form of presentation is subaxial subluxation (SAS), with pain, radiculopathy or even myelopathy secondary to canal stenosis. Multilevel subluxations can produce a "staircase" deformity, associated with severe systemic RA. 18,22,27

In this paper, we review and discuss the limitations and benefits of each radiological method used to diagnose cervical instability, as well as the criteria used to classify the most common forms of cervical spine involvement in RA.

\section{Overview of Imaging Modalities for Diagnosing Cervical Instabilities}

Routine plain radiographs are recommended for screening cervical instabilities in patients with RA, because there is a high prevalence of involvement and this imaging modality is widely available and relatively inexpensive. ${ }^{27,38,44}$ The standard plain radiographic screening views include upright anteroposterior, lateral, and flexionextension views and an open-mouth view for odontoid visualization. ${ }^{27,38,44}$ Bone alignment, quality, and deformities can easily be assessed with plain radiographs, but plain radiographs are limited in their ability to visualize bony erosions, the craniocervical and cervicothoracic junctions (due to superimposition of the cranial base structures and the glenohumeral joints), and soft tissue abnormalities such as pannus and spinal cord compression. If any cervical spine disease is suspected or confirmed with plain radiographs or the patient has any neurological symptom or important cervical pain, then CT and/or MRI examination of the cervical spine is indicated. 2,18,26,40

A CT scan with multiplanar reconstruction is the method of choice for detailed bony evaluation (including visualization of erosions, anatomy, and the presence of ankylosis and pseudarthrosis). For this reason, CT is important for surgical planning. However, soft tissue evaluation is limited in this imaging modality, and its ability to visualize the spinal cord and the nerve roots is poor. ${ }^{18,35}$

Finally, MRI is the most sensitive modality for detection of cervical spine involvement in RA and should be performed in all patients with anomalies detected or suspected on plain radiographs. ${ }^{45}$ A cervical MRI study should also be performed in all patients with myelopathy or radiculopathy. The benefits of MRI will be discussed further below. . $^{10,21,36}$

In Table 1 we presented a summary of the advantages and disadvantages of each imaging modality used to evaluate cervical instabilities in the setting of RA.

\section{Plain Radiographs}

\section{Screening for AAS and Cranial Settling}

The classical diagnostic measurements for AAS are based on plain radiographs. Of note, most of these criteria were published before the advent of modern CT and MRI, which can clearly visualize subluxation of the facet joints and all the bony landmarks of the craniocervical junction. . $9,12,24,29,30$ However, the craniocervical relationships proposed in the plain radiography era are still used for the initial evaluation, avoiding the cost of routine CT or MRI. Some of these plain radiographic criteria are presented below.

\section{Anterior Atlantodental Interval}

The normal value of the anterior atlantodental interval (ADI) - the distance from the posterior border of the anterior tubercle of the atlas to the dens-is less than $3 \mathrm{~mm}$ in healthy adults ${ }^{18}$ (Fig. 1). As the ADI increases, the chance of spinal cord compression progressively increases. Some authors report that when the anterior ADI exceeds $8 \mathrm{~mm}$, surgery is recommended, as this value suggests total rupture of the transverse and alar ligaments. ${ }^{5}$ However, most no longer use the anterior ADI for evaluating patients with RA, as the posterior ADI has been found to be a better predictor of paralysis and recovery.

\section{Posterior Atlantodental Interval}

The posterior ADI-the distance from the posterior border of the dens to the anterior aspect of the posterior arch of $\mathrm{C}-1$-evaluates the maximum amount of space available for the upper cervical spinal cord. This has been found to be a better predictor of the neurological risk and recovery in the setting of atlantoaxial subluxation (AAS) than the $\mathrm{ADI}^{5}$ (Fig. 1). The posterior ADI represents the anteroposterior diameter of the spinal canal at this level. In the cervical spine, the cord itself occupies $10 \mathrm{~mm}$ of the canal diameter. In addition, it requires $1 \mathrm{~mm}$ for the dura and $1 \mathrm{~mm}$ for the CSF anterior to the cord, and the same posteriorly, for a total of $14 \mathrm{~mm}$. Therefore, if the available space is less than $14 \mathrm{~mm}$, the cord becomes compressed.

The posterior ADI and anterior ADI should both be measured on images obtained in flexion and extension. Boden et al. found that patients with a posterior ADI greater than $14 \mathrm{~mm}$ had a higher rate of neurological recovery after fusion and stabilization, whereas a posterior ADI less than $10 \mathrm{~mm}$ was associated with worse clinical outcome. ${ }^{5}$

Neither the anterior ADI nor the posterior ADI can evaluate cord compression by soft tissues, such as a pannus formation in the retro-odontoid region. For this reason, spinal cord compression can occur even when the plain radiographic measurements are in the normative range.

\section{Lateral Displacement of the Atlas Over the Axis}

The open-mouth view is useful for evaluating lateral AAS. Rotatory AAS should be suspected when there is asymmetry or lateral displacement of the atlas on the axis by more than $2 \mathrm{~mm}$ in an open-mouth view. ${ }^{1}$ It should also be suspected when there is asymmetrical collapse of the lateral atlas mass. ${ }^{1}$ Lateral displacement can also occur with fractures of the dens. A CT scan should be performed to confirm the diagnosis.

\section{Cranial Settling}

Cranial settling is also known as basilar impression, at- 
TABLE 1: Summary of the advantages and disadvantages of each imaging modality used in the evaluation of cervical instabilities in the setting of RA

\begin{tabular}{|c|c|c|}
\hline Modality & Advantages & Disadvantages \\
\hline Plain radiographs & $\begin{array}{l}\text { Lower cost } \\
\text { Widely available } \\
\text { Screening of asymptomatic patients } \\
\text { Low radiation dose } \\
\text { Good for evaluation spinal alignment } \\
\text { Flexion \& extension allow visualization of occult instabilities }\end{array}$ & $\begin{array}{l}\text { Poor anatomical detail, especially at craniocervical \& cervicothoracic } \\
\text { junction } \\
\text { Poor soft tissue visualization } \\
\text { Poor visualization of bone erosions }\end{array}$ \\
\hline $\begin{array}{l}\text { CT w/ multiplanar } \\
\text { reconstruction }\end{array}$ & $\begin{array}{l}\text { Widely available } \\
\text { Gold standard for bone evaluation } \\
\text { Good for evaluation of ankylosis \& pseudarthrosis } \\
\text { Useful for surgical planning } \\
\text { Flexion \& extension allow visualization of occult instabilities }\end{array}$ & $\begin{array}{l}\text { Higher cost compared to plain radiographs } \\
\text { Higher dose of radiation (relative contraindication during pregnancy) } \\
\text { Risks w/ intravenous injection of iodinated contrast } \\
\text { Requires sedation for young or claustrophobic patients } \\
\text { Poor evaluation of soft tissues \& spinal cord }\end{array}$ \\
\hline MRI & $\begin{array}{l}\text { Gold standard for soft tissue \& spinal cord evaluation } \\
\text { Most sensitive \& specific for cervical instabilities } \\
\text { Flexion \& extension allow visualization of occult instabilities } \\
\text { Best for evaluation of patients w/ neurological deficits }\end{array}$ & $\begin{array}{l}\text { Highest cost of all imaging modalities } \\
\text { Requires sedation for young or claustrophobic patients } \\
\text { Risk w/ intravenous injection of gadolinium, especially in patients w/ } \\
\text { kidney diseases (nephrogenic systemic fibrosis) } \\
\text { May be contraindicated in patients w/ implanted pacemakers, stimu- } \\
\text { lators, \& incompatible pumps, clips, pins, \& plates }\end{array}$ \\
\hline
\end{tabular}

lantoaxial impaction, superior migration of the odontoid, and vertical subluxation, and there are numerous plain radiographic criteria for making the diagnosis in RA patients.

The diagnosis of cranial settling based on plain radiographs is sometimes a challenge for radiologists and physicians, as osseous structures of the cranial base are superimposed upon the landmarks, especially in the upper cervical spine. ${ }^{32}$ Furthermore, erosion of the dens can make it difficult, if not impossible, to identify its tip. Finally, although the terms "basilar invagination" and "basilar impression" are used synonymously by many authors, the former term may be better used when referring to a congenital craniocervical junction anomaly, whereas basilar

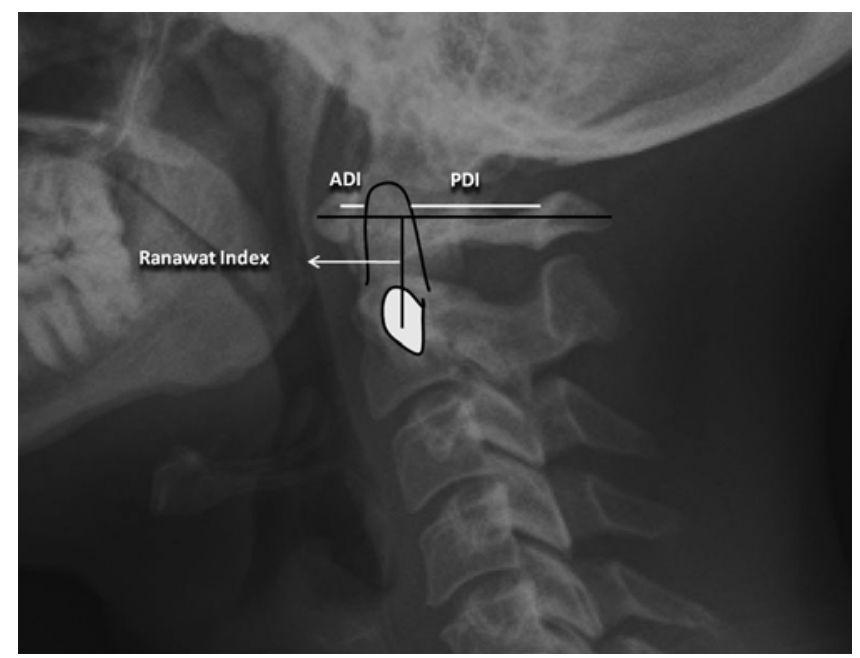

FIG. 1. Lateral plain radiograph showing the anterior atlantodental interval (designated in this image by ADI) and the posterior atlantodental interval (designated in this image by PDI) as well as the Ranawat index, the distance from the center of the C-2 pedicle to the transverse axis of C-2. impression is more accepted for the description of secondary causes of cranial settling, as occurs in RA.

Below, we list some of the many plain radiographic criteria to diagnose basilar impression that have been described in the literature and their original dates of publication (see also Figs. 1-6).

Chamberlain line (1939): Findings are considered positive if the apex of the odontoid is $3 \mathrm{~mm}$ above a line from the posterior edge of the hard palate to the opisthion. ${ }^{8}$

McGregor line (1948): Findings are considered positive if the apex of the odontoid is $>4.5 \mathrm{~mm}$ above a line drawn from the posterior hard palate to the most inferior point on the occipital curve. ${ }^{23}$

Fischgold and Metzger line (1952): Findings are positive if the apex of the odontoid is above the line connecting the tips of the mastoid processes bilaterally in an openmouth view. ${ }^{11}$

McRae line (1953): Findings are positive if the tip of the odontoid extends above a line drawn from the basion (anterior rim of the foramen magnum) to the opisthion (posterior rim of the foramen magnum). ${ }^{24}$

Wackenheim line (1974): Findings are positive if the odontoid protrudes posterior to a line drawn extending from the superior surface of the clivus through the spinal canal. ${ }^{37}$

Ranawat criterion (1979): A line is drawn from the midpoint of the $\mathrm{C}-2$ pedicle along the center of the odontoid process until it intersects a horizontal line through the atlas. Findings are positive if the length is $<15 \mathrm{~mm}$ in males or $<13 \mathrm{~mm}$ in females. ${ }^{29}$

Redlund-Johnell criterion (1984): A line is drawn from the midpoint of the caudal surface of the C-2 body to the McGregor line.$^{30}$ Findings are considered positive if the length is $<34 \mathrm{~mm}$ in males or $<29 \mathrm{~mm}$ in females.

Clark station (1989): The odontoid process is divided into 3 equal parts ("stations") from craniad to caudad in the sagittal plane. ${ }^{9}$ The results are positive if the anterior arch of the atlas is in the second or third station. This 


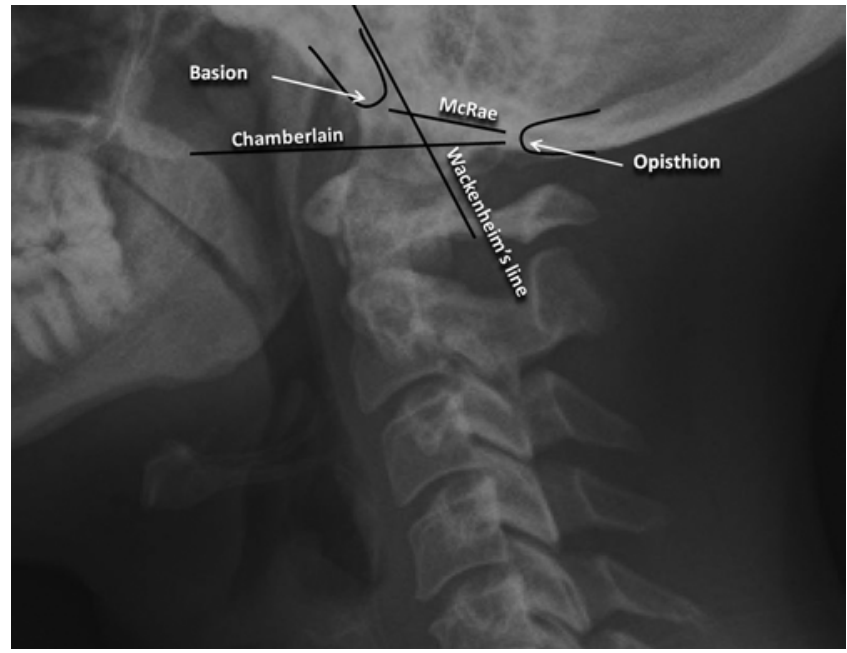

FIG. 2. Lateral plain radiograph showing the McRae, Chamberlain, and Wackenheim lines for evaluation of the relationships between the occiput, C-1, and C-2.

method is the simplest one, as the relationship does not change in flexion, extension, or neutral views.

Riew et al. ${ }^{32}$ evaluated the reliability and sensitivity of the diagnosis of basilar invagination in 131 cervical radiographs obtained in patients with RA, according to the criteria proposed by Clark et al., McRae and Barnum, Chamberlain, McGreger, Redlund-Johnell and Pettersson, Ranawat et al., Fischgold and Metzger, and Wackenheim. As a final conclusion, no single plain radiographic criteria had sensitivity and a negative predictive value greater than $90 \%$ as well as a reasonable specificity and acceptable positive predictive value. Therefore, they suggested that the results of screening for basilar impression should be considered positive when at least one of 3 following criteria are positive: the Clark station, the Redlund-Johnell criterion, or the Ranawat criterion. The use of the combined criteria improved the sensitivity to $94 \%$ and the negative predictive value to $91 \%$. If at least one of the 3 is positive,

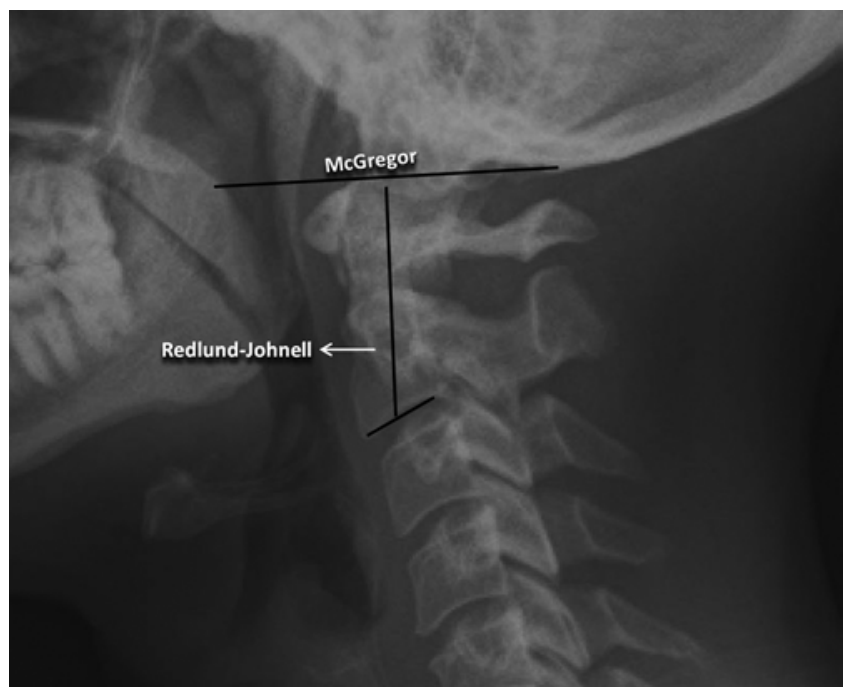

FIG. 3. Lateral plain radiograph showing the McGregor line and the Redlund-Johnell measurement from the McGregor line to the midpoint of the caudal margin of the $\mathrm{C}-2$ body.

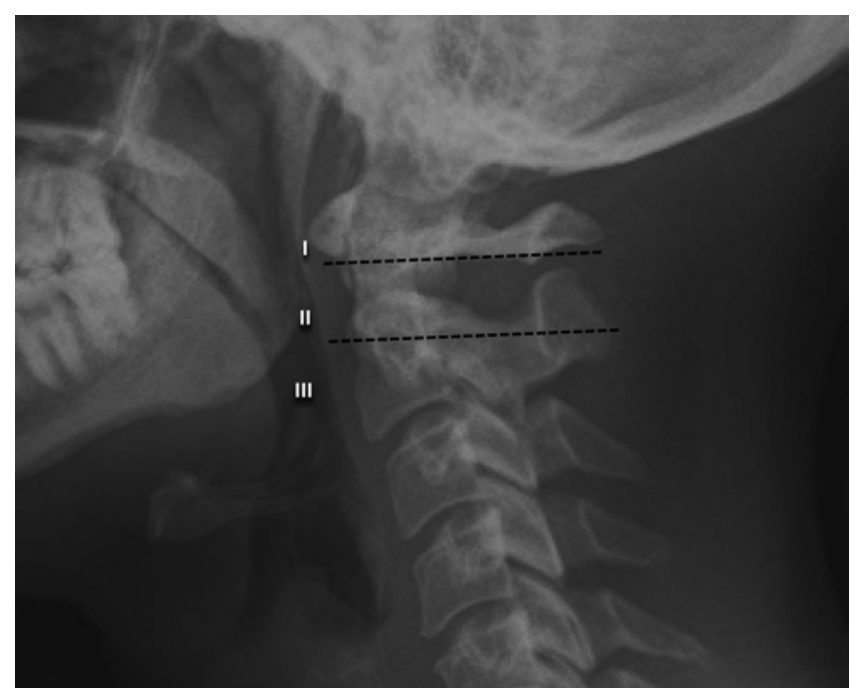

FIG. 4. Lateral plain radiograph showing the Clark stations. The odontoid process is divided into 3 equal parts or stations. The position of the anterior arch of the atlas is assessed relative to these stations.

a CT scan or an MRI should be performed. Figures 1-4 depict the various plain radiographic measurements for assessing the upper cervical spine.

\section{Screening for SAS}

Subaxial subluxation (SAS) commonly occurs in RA patients after degeneration of the ligamentous structures, such as the facet joints, the intervertebral disc, and interspinous ligaments. ${ }^{38}$ Anterior SAS is much more common than posterior SAS. Subaxial subluxation can be an isolated finding involving one or multiple levels, but not uncommonly, it is associated with antlantoaxial subluxation (AAS). White et al. proposed that biomechanical instability for SAS occurs when there is more than $3.5 \mathrm{~mm}$ of horizontal displacement of one vertebra in relation to an adjacent vertebra measured on lateral radiographs. ${ }^{39}$ However, some authors report that even $2 \mathrm{~mm}$ of anterior subluxation increases the risk of cervical spinal cord injury. ${ }^{41,43}$ As proposed by Yurube et al., the diagnosis of SAS should be considered when an irreducible translation of more than $2 \mathrm{~mm}$ is documented, and severe SAS occurs when there is more than $4 \mathrm{~mm}$ of translation. ${ }^{43}$ Some
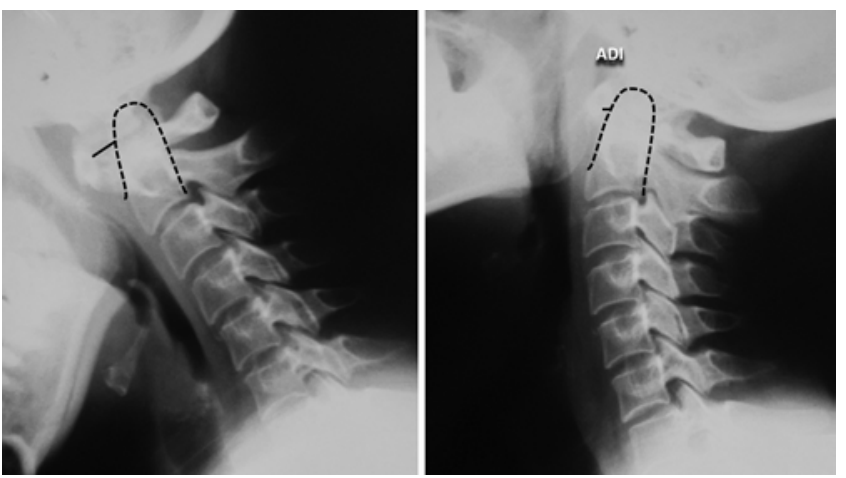

FIG. 5. Lateral cervical flexion (left) and extension (right) radiographs obtained in a patient with RA and cervical pain refractory to nonsurgical treatment. Note the increase (in flexion) of the anterior ADI, confirming an atlantoaxial instability. 

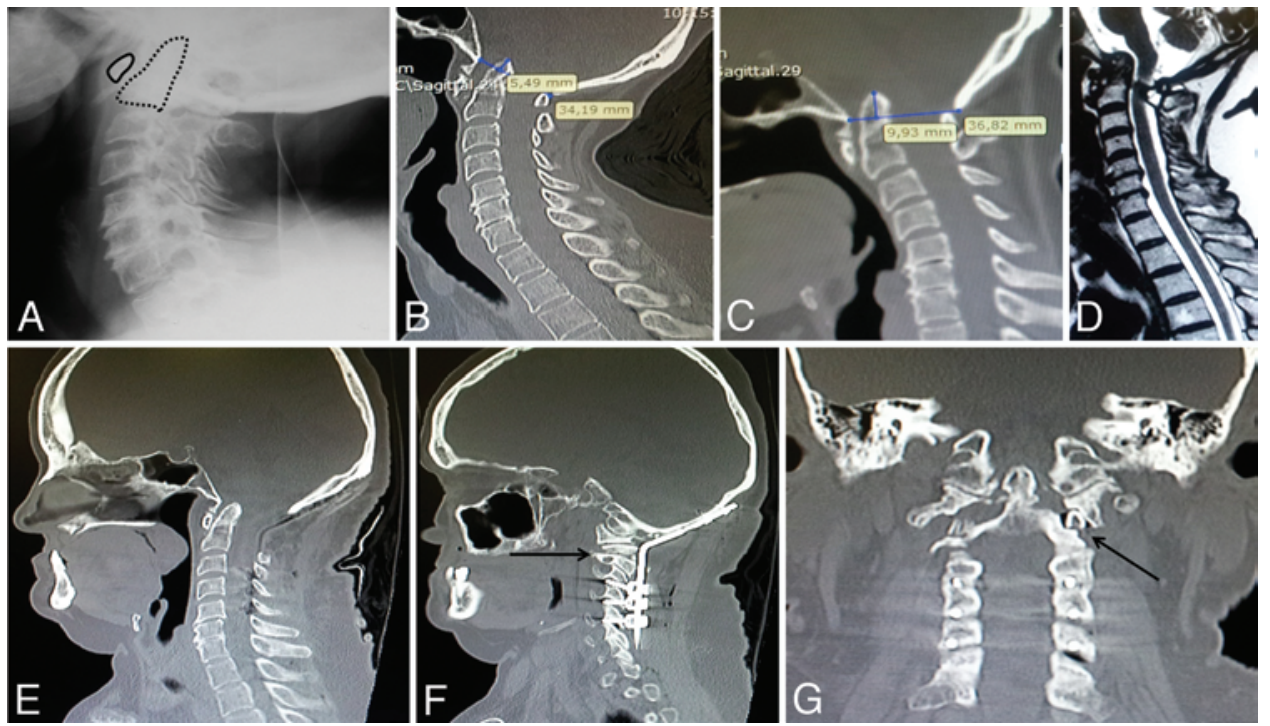

FIG. 6. Preoperative and postoperative images obtained in a 53-year-old patient with severe RA. A: Lateral cervical radiograph showing the dens protruding into the foramen magnum, with basilar impression. B and C: CT images obtained in extension (B) showing the tip of the dens $5.49 \mathrm{~mm}$ above the McRae line and in flexion (C) showing the dens $9.43 \mathrm{~mm}$ above the McRae line. D: Sagittal T2-weighted MR image showing the dens protruding into the medulla and posterior compression of the upper spinal cord by the posterior arch of the atlas. E: Sagittal reconstruction of postoperative CT scan obtained after occipitocervical decompression and craniocervical fixation. F and G: Sagittal and coronal CT reconstructions showing the autologous bone graft (black arrow) used as a spacer between $\mathrm{C}-1$ and $\mathrm{C}-2$ to reduce the protrusion of the tip of the odontoid process into the foramen magnum.

authors report that the clinical outcome of patients with SAS is worse than those with AAS, generally with late neurological deterioration even after surgery. ${ }^{25}$

Similar to the spinal canal at the atlantoaxial level, the subaxial spinal canal sagittal diameter must have at least $14 \mathrm{~mm}$ to avoid cord compression. The normal diameter measured on lateral radiographs from C-3 to C-7 is 14-23 $\mathrm{mm}$, and the diameter of the canal is a better predictor of neurological impairment than the degree of subluxation between the vertebrae. ${ }^{10,12}$

\section{CT With Multiplanar Reconstruction}

The best radiological modality for evaluating bone anatomy is 3D CT with multiplanar reconstruction. The reformatted sagittal CT scan can precisely document the position of the odontoid with respect to the foramen magnum, the degree of atlantoaxial dislocation, and the relationships among the upper cervical spine joints. ${ }^{14}$ In addition, CT allows for accurate visualization of bony erosions, ankylosis, pseudarthrosis, and vertebral collapse. Rotational instabilities are also well visualized, especially with 3D reconstructions. CT is also helpful in planning the best surgical technique to be used in each case and assessing the size of the implants to be used. It is used to determine the type of fixation that can be used, such as C-1 posterior arch versus lateral mass screws or C-2 pars, pedicle, or laminar screws. ${ }^{16}$

Another use of CT is, in combination with angiography, to evaluate the vertebral artery anatomy. This test can be extremely important for some surgical techniques, such as C-2 pedicle screw fixation.

A contrast-enhanced CT scan can be useful to diagnose inflammatory soft tissue proliferation in patients unable to undergo MRI (contraindications for MRI may include
MRI-incompatible aneurysm clips, incompatible body implants, wires or plates used for bone synthesis, some heart valves and some implanted electrodes). ${ }^{10}$

Dynamic CT scans can demonstrate occult instabilities, especially in the craniocervical and cervicothoracic regions that are poorly visualized by flexion-extension plain radiographs due to superimposed bony structures. ${ }^{3,31}$

Younes et al. performed a study on the prevalence of cervical spine instabilities in RA patients according to the radiological modality used. ${ }^{42}$ A total of 40 patients with RA and at least 2 years of disease underwent standard radiography, CT, and MRI. Spinal involvement was found in 29 patients $(72.5 \%)$, and the authors reported that although MRI was the best modality to diagnose $\mathrm{C} 1-2$ pannus, dens erosion, and neurological impact of RA, CT was the best technique to visualize atypical rotational or lateral AAS. This study confirms the advantages of both radiological studies in the diagnosis of cervical RA involvement and the complementary value of both for a complete evaluation.

\section{Magnetic Resonance Imaging}

MRI is the modality of choice for early diagnosis of cervical involvement, because it has high sensitivity in detecting inflammatory changes in the joints-synovial changes and pannus formation-even before instability develops. ${ }^{36}$ MRI can provide information about the soft tissues, including the neural tissue (spinal cord and nerve roots) and the contents of the epidural space, and it is the modality of choice in evaluating spinal cord compression. The triplanar images obtained with MRI can also precisely document the craniocervical relationships, with direct visualization of facet subluxations, joint destruction, and dens dislocation. ${ }^{34}$ 
A cervical MRI with contrast enhancement should be performed in all patients with neurological deficits or abnormalities detected on plain radiographs. MRI is also recommended to evaluate the cervicomedullary angle: patients with a measurement of less than $135^{\circ}$ for this angle had the diagnosis of cranial settling and myelopathy in one study. ${ }^{7,31}$ Dynamic MRI can also be particularly useful in patients with RA. Images obtained in flexion can demonstrate clinically significant narrowing of the subarachnoid space at the atlantoaxial level and below, when images obtained in the neutral position show adequate space. In a 1998 study by Allmann et al., ${ }^{3}$ narrowing that was not apparent in images obtained in the neutral position was identified on flexion images in $12 \%$ of cases. Similarly, cord compression not evident in the neutral position was identified in extension images in $12 \%$ of cases. Flexion and extension MRI can be performed in patients with clinical signs of myelopathy or cervical pain but without radiological changes in neutral MRI and flexion and extension plain radiographs.

In addition to the utility of MRI for diagnosis, MRI changes can be useful for prognosis: T1-weighted spinal cord signal changes are associated with poor clinical status and also poor final postoperative outcome. , $31^{2}$

Another potential benefit of this imaging modality is in the evaluation of pannus regression after surgical treatment. Since pannus formation is probably secondary to articular hypermobility, fusion of the affected joint can result in pannus regression (especially in cases with contrast enhancement). ${ }^{20}$

Finally, MRI can evidence cervical stenosis even when there is no evident SAS. Patients with RA can present with subaxial stenosis due to inflammatory tissue in the anterior or posterior canal space, documented with contrastenhanced MRI. This tissue is considered to be a form of pannus, probably secondary to inflammation and excessive hypermobility due to joint destruction. ${ }^{19}$

\section{Conclusions}

In patients without significant clinical symptoms, screening with plain radiographs is recommended. Knowledge of the craniocervical relationships based on plain radiographs is critical to diagnose cervical instabilities, especially atlantoaxial subluxation and basilar impression.

MRI is the best imaging modality to diagnose cervical involvement in RA. It can identify spinal cord compression as well as inflammatory changes. CT scan can provide detailed bone anatomy evaluation, which can be extremely useful for surgical planning. Dynamic CT and MRI can diagnose occult instabilities and provide additional information for treatment. Multimodality radiological evaluation is necessary for an accurate diagnosis as well as treatment planning.

\section{References}

1. Aggarwal A, Kulshreshtha A, Chaturvedi V, Misra R: Cervical spine involvement in rheumatoid arthritis: prevalence and relationship with overall disease severity. J Assoc Physicians India 44:468-471, 1996

2. Ahn JK, Hwang JW, Oh JM, Lee J, Lee YS, Jeon CH, et al: Risk factors for development and progression of atlantoaxial subluxation in Korean patients with rheumatoid arthritis. Rheumatol Int 31:1363-1368, 2011

3. Allmann KH, Uhl M, Uhrmeister P, Neumann K, von Kempis J, Langer M: Functional MR imaging of the cervical spine in patients with rheumatoid arthritis. Acta Radiol 39: 543-546, 1998

4. Blom M, Creemers MC, Kievit W, Lemmens JA, van Riel PL: Long-term follow-up of the cervical spine with conventional radiographs in patients with rheumatoid arthritis. Scand J Rheumatol 42:281-288, 2013

5. Boden SD, Dodge LD, Bohlman HH, Rechtine GR: Rheumatoid arthritis of the cervical spine. A long-term analysis with predictors of paralysis and recovery. J Bone Joint Surg Am 75:1282-1297, 1993

6. Bogduk N, Major GA, Carter J: Lateral subluxation of the atlas in rheumatoid arthritis: a case report and post-mortem study. Ann Rheum Dis 43:341-346, 1984

7. Bundschuh C, Modic MT, Kearney F, Morris R, Deal C: Rheumatoid arthritis of the cervical spine: surface-coil MR imaging. AJR Am J Roentgenol 151:181-187, 1988

8. Chamberlain WE: Basilar impression (platybasia): a bizarre developmental anomaly of the occipital bone and upper cervical spine with striking and misleading neurologic manifestations. Yale J Biol Med 11:487-496, 1939

9. Clark CR, Goetz DD, Menezes AH: Arthrodesis of the cervical spine in rheumatoid arthritis. J Bone Joint Surg Am 71:381-392, 1989

10. Czerny C, Grampp S, Henk CB, Neuhold A, Stiskal M, Smolen J: Rheumatoid arthritis of the craniocervical region: assessment and characterization of inflammatory soft tissue proliferations with unenhanced and contrast-enhanced CT. Eur Radiol 10:1416-1422, 2000

11. Fischgold H, Metzger J: [Radio-tomography of the impression fractures of the cranial basis.] Rev Rhum Mal Osteoartic 19:261-264, $1952(\mathrm{Fr})$

12. Gurley JP, Bell GR: The surgical management of patients with rheumatoid cervical spine disease. Rheum Dis Clin North Am 23:317-332, 1997

13. Hamilton JD, Gordon MM, McInnes IB, Johnston RA, Madhok R, Capell HA: Improved medical and surgical management of cervical spine disease in patients with rheumatoid arthritis over 10 years. Ann Rheum Dis 59:434-438, 2000

14. Holmes JF, Akkinepalli R: Computed tomography versus plain radiography to screen for cervical spine injury: a metaanalysis. J Trauma 58:902-905, 2005

15. Joaquim AF, Appenzeller S: Cervical spine involvement in rheumatoid arthritis - a systematic review. Autoimmun Rev 13:1195-1202, 2014

16. Joaquim AF, Ghizoni E, Anderle DV, Oliveira Ed, Tedeschi H: Axis instrumentation: surgical results. Arq Neuropsiquiatr 70:857-863, 2012

17. Koopman WJ: Prospects for autoimmune disease: research advances in rheumatoid arthritis. JAMA 285:648-650, 2001

18. Krauss WE, Bledsoe JM, Clarke MJ, Nottmeier EW, Pichelmann MA: Rheumatoid arthritis of the craniovertebral junction. Neurosurgery 66 (3 Suppl):83-95, 2010

19. Kroft LJ, Reijnierse M, Kloppenburg M, Verbist BM, Bloem JL, van Buchem MA: Rheumatoid arthritis: epidural enhancement as an underestimated cause of subaxial cervical spinal stenosis. Radiology 231:57-63, 2004

20. Landi A, Marotta N, Morselli C, Marongiu A, Delfini R: Pannus regression after posterior decompression and occipito-cervical fixation in occipito-atlanto-axial instability due to rheumatoid arthritis: case report and literature review. Clin Neurol Neurosurg 115:111-116, 2013

21. Magarelli N, Simone F, Amelia R, Leone A, Bosello S, D'Antona $\mathrm{G}$, et al: MR imaging of atlantoaxial joint in early rheumatoid arthritis. Radiol Med 115:1111-1120, 2010

22. Matteson EL: Cervical spine disease in rheumatoid arthritis: 
how common a finding? How uncommon a problem? Arthritis Rheum 48: 1775-1778, 2003

23. McGregor M: The significance of certain measurements of the skull in the diagnosis of basilar impression. Br J Radiol 21:171-181, 1948

24. McRae DL, Barnum AS: Occipitalization of the atlas. Am J Roentgenol Radium Ther Nucl Med 70:23-46, 1953

25. Miyamoto H, Sumi M, Uno K: Outcome of surgery for rheumatoid cervical spine at one institute over three decades. Spine J 13:1477-1484, 2013

26. Narváez JA, Narváez J, Serrallonga M, De Lama E, de Albert M, Mast R, et al: Cervical spine involvement in rheumatoid arthritis: correlation between neurological manifestations and magnetic resonance imaging findings. Rheumatology (Oxford) 47:1814-1819, 2008

27. Neva MH, Häkkinen A, Mäkinen H, Hannonen P, Kauppi M, Sokka T: High prevalence of asymptomatic cervical spine subluxation in patients with rheumatoid arthritis waiting for orthopaedic surgery. Ann Rheum Dis 65:884-888, 2006

28. Nguyen HV, Ludwig SC, Silber J, Gelb DE, Anderson PA, Frank L, et al: Rheumatoid arthritis of the cervical spine. Spine J 4:329-334, 2004

29. Ranawat CS, O'Leary P, Pellicci P, Tsairis P, Marchisello P, Dorr L: Cervical spine fusion in rheumatoid arthritis. J Bone Joint Surg Am 61:1003-1010, 1979

30. Redlund-Johnell I, Pettersson H: Radiographic measurements of the cranio-vertebral region. Designed for evaluation of abnormalities in rheumatoid arthritis. Acta Radiol Diagn (Stockh) 25:23-28, 1984

31. Reijnierse M, Breedveld FC, Kroon HM, Hansen B, Pope TL, Bloem JL: Are magnetic resonance flexion views useful in evaluating the cervical spine of patients with rheumatoid arthritis? Skeletal Radiol 29:85-89, 2000

32. Riew KD, Hilibrand AS, Palumbo MA, Sethi N, Bohlman $\mathrm{HH}$ : Diagnosing basilar invagination in the rheumatoid patient. The reliability of radiographic criteria. J Bone Joint Surg Am 83-A:194-200, 2001

33. Shen FH, Samartzis D, Jenis LG, An HS: Rheumatoid arthritis: evaluation and surgical management of the cervical spine. Spine J 4:689-700, 2004

34. Stiskal MA, Neuhold A, Szolar DH, Saeed M, Czerny C, Leeb B, et al: Rheumatoid arthritis of the craniocervical region by MR imaging: detection and characterization. AJR Am J Roentgenol 165:585-592, 1995

35. Sugita S, Chikuda H, Kadono Y, Ohtsu H, Takeshita K, Nishino J, et al: Clinical characteristics of rheumatoid arthritis patients undergoing cervical spine surgery: an analysis of National Database of Rheumatic Diseases in Japan. BMC Musculoskelet Disord 15:203, 2014

36. Tehranzadeh J, Ashikyan O, Dascalos J: Magnetic resonance imaging in early detection of rheumatoid arthritis. Semin Musculoskelet Radiol 7:79-94, 2003

37. Wackenheim A: Roentgen Diagnosis of the Craniovertebral Region. New York: Springer, 1974

38. Wasserman BR, Moskovich R, Razi AE: Rheumatoid arthritis of the cervical spine-clinical considerations. Bull NYU Hosp Jt Dis 69:136-148, 2011

39. White AA III, Johnson RM, Panjabi MM, Southwick WO: Biomechanical analysis of clinical stability in the cervical spine. Clin Orthop Relat Res (109):85-96, 1975

40. Yan WJ, Liu TL, Zhou XH, Chen XS, Yuan W, Jia LS: [Clinical characteristics and diagnosis of rheumatoid arthritis of upper cervical spine: analysis of 71 cases.] Zhonghua Yi Xue Za Zhi 88:901-904, 2008 (Chinese)

41. Yonezawa T, Tsuji H, Matsui H, Hirano N: Subaxial lesions in rheumatoid arthritis. Radiographic factors suggestive of lower cervical myelopathy. Spine (Phila Pa 1976) 20:208215,1995

42. Younes M, Belghali S, Kriâa S, Zrour S, Bejia I, Touzi M, et al: Compared imaging of the rheumatoid cervical spine: prevalence study and associated factors. Joint Bone Spine 76:361-368, 2009

43. Yurube T, Sumi M, Nishida K, Miyamoto H, Kohyama K, Matsubara T, et al: Incidence and aggravation of cervical spine instabilities in rheumatoid arthritis: a prospective minimum 5-year follow-up study of patients initially without cervical involvement. Spine (Phila Pa 1976) 37:2136-2144, 2012

44. Zikou AK, Alamanos Y, Argyropoulou MI, Tsifetaki N, Tsampoulas C, Voulgari PV, et al: Radiological cervical spine involvement in patients with rheumatoid arthritis: a cross sectional study. J Rheumatol 32:801-806, 2005

45. Zoli A, Priolo F, Galossi A, Altomonte L, Di Gregorio F, Cerase A, et al: Craniocervical junction involvement in rheumatoid arthritis: a clinical and radiological study. J Rheumatol 27:1178-1182, 2000

\section{Author Contributions}

Conception and design: Joaquim, Ghizoni. Acquisition of data: Joaquim. Analysis and interpretation of data: all authors. Drafting the article: Joaquim, Appenzeller, Riew. Critically revising the article: all authors. Reviewed submitted version of manuscript: all authors. Approved the final version of the manuscript on behalf of all authors: Joaquim.

\section{Correspondence}

Andrei Fernandes Joaquim, Antônio Lapa St. 280, Sala 506. Cambuí, Campinas-SP 13025-240, Brazil. email: andjoaquim@ yahoo.com. 